\title{
RAVENS PULLING WOOL FROM SHEEP
}

RICHARD A. STARDOM, Wildlife Branch, Box 24, 200 Saulteaux Crescent, Winnipeg MB R3J $3 W 3$

Common Ravens regularly line their nests with hair from a variety of mammals, including deer, moose, musk-ox, cattle, horses, skunks, dogs, and, yes, sheep, presumably collecting from dead animals or gathering stray tufts of hair and wool. ${ }^{1}$ Active pulling of wool from live sheep by ravens, however, seems worth noting.

During the winters of 1994-95 and 199596 , two to five ravens were often observed in tall aspens along the southern perimeter of our hobby farm site about $30 \mathrm{~km}$ north of Winnipeg. By about February, they were reduced to one pair. At that time there were only three to four sheep and a cow and two calves in the pasture, plus miscellaneous numbers of chickens and turkeys in a semifree range situation.

In late winter, 1996-97, after we acquired an additional dozen sheep and their lambs, a pair of ravens was again observed. On one occasion, one raven walked about the pasture picking up stray bits of wool, then flew to the other raven and presented the wool. That second bird, presumably the female, was usually perched on the roof peak of either a wooden granary in the pasture or a barn just outside the pasture. After the wool presentation ceremony, the two flew away together.

In February and March 1998, the pair of ravens frequenting the pasture could have been the same pair as the three previous winters, though we had no way of knowing that. The same process of collecting and presenting wool took place in February. This changed, however, after March 7, when they became more aggressive in their wool acquisition.

I observed two ravens on our bale feeder amongst the sheep. Again, it appeared that one raven was the collector and the other supervised the process. One raven would

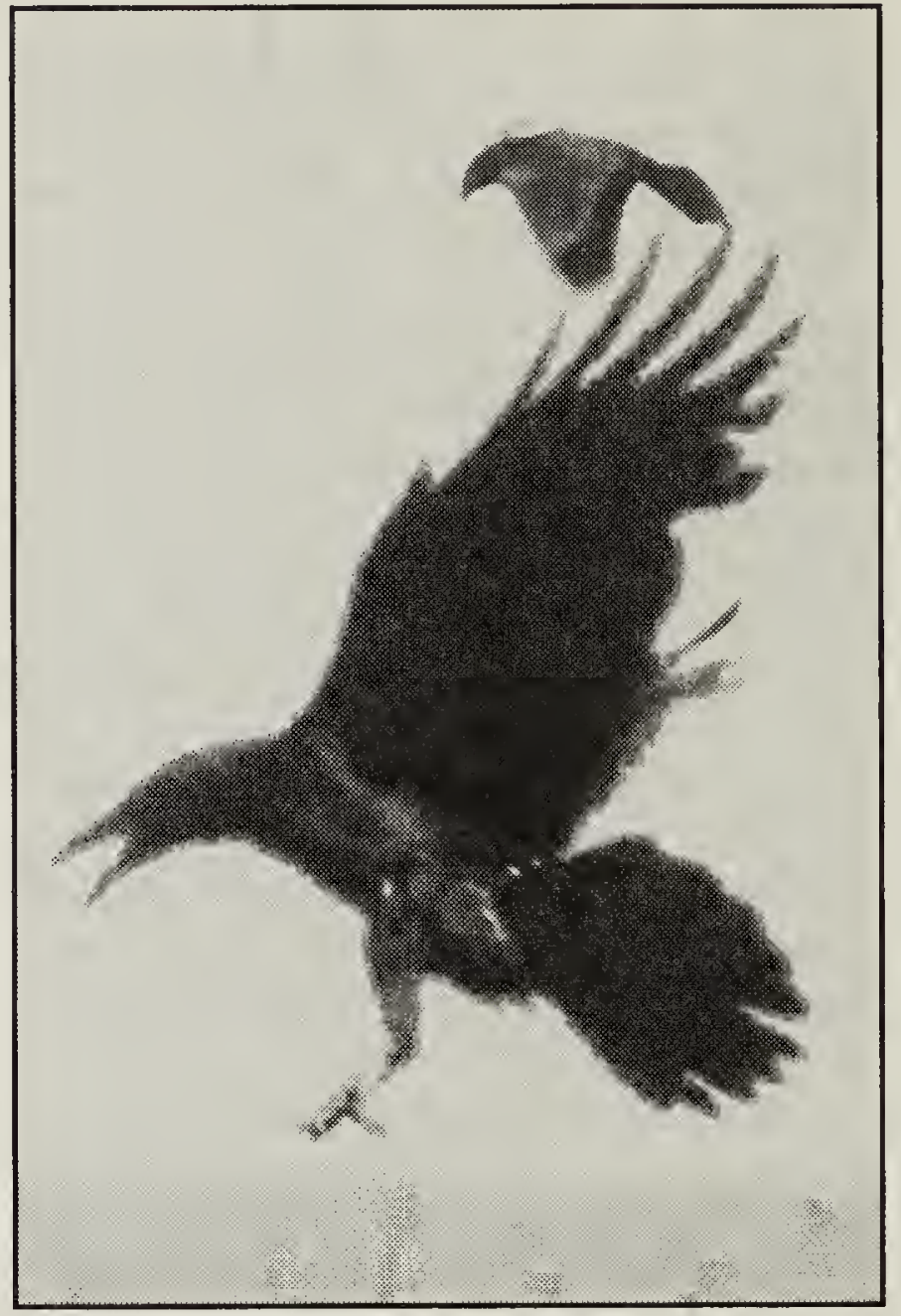

Red-winged Blackbird attacking Common Raven

Photo by Robert J. Long

hop off the bale feeder onto the back of a sheep and then proceed to actually pull wool from the sheep's back. Although the raven was energetically tugging at its wool the sheep did not react in any way. When sufficient amounts of wool had been plucked, both ravens would fly to a tree in the pasture, whereupon one (the collector) would consolidate it and the pair would then fly away.

Since I assumed that the ravens were only picking shedding wool, I was not concerned, and was merely fascinated by the behaviour. However, when feeding the sheep their oats, I noticed that patches on the backs of three of the sheep were completely lacking wool; only the short half-inch-long underwool 
remained. On one sheep, more than 100 $\mathrm{cm}^{2}$ (sixteen square inches) of its back was bare. Although probably not a problem during warm weather, this could have an adverse impact in cold weather, particularly when sheep are nursing lambs and require high energy reserves.

Upon enquiry, University of Vermont zoologist Bernd Heinrich, a noted raven observer, had this to say about the above observations: "Yes, the bird was collecting nest lining." Professor Heinrich added that similar behaviour, wool gathering by ravens from live sheep, had been observed in Vermont, as discussed in his new book Mind of the Raven (Personal correspondence, July 2, 1999, R.W. Nero.) ${ }^{2}$

\section{Acknowledgements}

Bob Nero corresponded with Bernd Heinrich on my behalf. I thank Jim Duncan and Bob Nero for editorial improvements, and Cindy Little for typing the manuscript.

Bent, A. C. 1946. Life histories of North American jays, crows and titmice. U.S. Natl. Mus. Bull. 191, part 1.

Heinrich, B. 1999. Mind of the raven: Investigations and adventures with wolf-birds. Harper Collins, Toronto.

"Of the approximately 130 species of butterflies recorded from the New York city area, 32 are listed on the "Endangered and Threatened Butterflies" list of the

New York City Butterfly Club. Nine of these species have not been recorded in the New York City area for the last ten years."

"Because most butterfly populations do not need very large expanses of habitat, preservation of most species is feasible by creating an interconnecting network of small protected habitat units along with a few larger units." 